\title{
Retiring Categorical Systems and the Biomedical Model of Mental Illness: The Why and the How-A Clinician's Perspective
}

\author{
Sebastian Salicru \\ PTS Psychology, Canberra, Australia \\ Email: s@pts.net.au
}

How to cite this paper: Salicru, S. (2020). Retiring Categorical Systems and the Biomedical Model of Mental Illness: The Why and the How-A Clinician's Perspective. Psychology, 11, 1215-1235.

https://doi.org/10.4236/psych.2020.118081

Received: July 27, 2020

Accepted: August 24, 2020

Published: August 27, 2020

Copyright $\odot 2020$ by author(s) and Scientific Research Publishing Inc. This work is licensed under the Creative Commons Attribution International License (CC BY 4.0).

http://creativecommons.org/licenses/by/4.0/ (c) (i) Open Access

\begin{abstract}
This article offers a transdiagnostic framework for the prevention and treatment of mental health by reducing early psychopathology. The framework supports the contention that the time has come to retire dominant categorical classification systems of mental disorders (e.g. DSM and ICD), and the current prevailing biomedical model of mental illness by moving to a psychosocial model of psychopathology. This entails reclaiming and integrating the long-standing legacy of psychology with recent advances in neuroscience and related disciplines. To this end, this conceptual paper synthesizes and integrates the extant literature and empirical findings, takes a scientist-practitioner stance, and draws on recent developments in transdiagnostic approaches to mental health, psychotherapy integration and advances in modern attachment theory. The advantages of this approach are that: 1) Clarifies the existing confusion surrounding the myriad of different interventions available; 2) Enables consistent funding guidelines from healthcare and community education systems; 3) Is more likely to have a greater positive impact for most people; 4) Reduces general psychopathology risks in childhood; 5) Avoids the challenge that prevention is less successful in later life; 6) Better addresses the stigma associated with mental illness; and 7) Maximizes the efficiency of interventions.
\end{abstract}

\section{Keywords}

Categorical Classification, DSM, Hierarchical Taxonomy of Psychopathology, "p" Factor, General Psychopathology, Transdiagnostic Prevention,

Psychotherapy Integration 


\section{Introduction}

The call made by psychologists and scholars to abandon the "Disease Model" of Mental Health and move to a "Psychosocial Model" abundant in the extant literature (Allsopp et al., 2019; Awenat et al., 2013; Bakker, 2019; Bentall, 2014; Deacon, 2013; Goldacre, 2014; Guerin, 2017; Hengartner \& Lehmann, 2017; Kinderman, 2017; Middleton, 2015; Pemberton \& Wainwright, 2014; Timimi, 2014) can no longer be ignored. Current traditional biomedical models that use categorical diagnostic approaches to mental health, such as those codified in the Diagnostic and Statistical Manual of Mental Disorders (DSM) - created by the American Psychiatric Association (APA), and the International Classification of Diseases (ICD) - developed by the World Health Organization (WHO), have wielded a strong legacy in academic research, the mental health industry, and society at large (Dalgleish et al., 2020). The developments of their respective latest editions, the DSM-5 and ICD-11, revived contentions related to the nosology of psychiatry (Stein et al., 2013). The DSM system, for example, has shaped the conceptualization of mental health and illness and preserved the medical identity of psychiatry by adhering to the doctrine of biomedicine (Kawa \& Giordano, 2012), and spawned from "a tradition filled with haphazard science and politically driven choices" (Shorter, 2015: p. 59). By maintaining that mental disorders are diseases of the brain and promoting pharmacological treatment to address assumed biological abnormalities (Deacon, 2013), the DSM system has become "the gold standard for mental health diagnosis" (Khoury et al., 2014: p. 1). This is despite the fact that numerous controversies exist related to the understanding and classification of psychopathology when using categorical systems. Most notably this includes their etiology, thresholds, and comorbidity (Clark et al., 2017). To begin, however, it is important to acknowledge that categorical approaches have provided important benefits.

\section{Benefits of Categorical Approaches}

There are, at least, three main benefits provided by the dominant taxonomic approach. First, the DSM system, for example, provides a shared language for the mental health global community by significantly reducing semantic confusion relating to psychiatric disorders (van Heugten-van der Kloet \& van Heugten, 2015). Second, it offers an organizing system that guides the training of mental health professionals around the world for the assessment, diagnosis, management and treatment of psychopathology. Third, like other biomedical models, the DSM system can be seen as reducing the stigma and personal weaknesses attributed to those individuals being diagnosed by bringing validation and legitimacy to their distress (Dalgleish et al., 2020). This issue related to stigma, however, constitutes a double-edged sword, as explained below.

\section{Criticisms of Categorical Approaches and the Biomedical Model}

Notwithstanding the above-mentioned benefits, categorical approaches have in- 
creasingly been subject to harsh criticisms for multiple reasons.

\subsection{Distinct, Episodic, and Categorical}

Traditionally, mental disorders have been conceptualized as distinct, episodic, and categorical. Both the DSM and ICD systems conceptualize mental disorders as polythetic and categorical concepts. The first, means that a specific mental disorder is defined by multiple symptoms, and not all symptoms are considered a mental disorder present in that specific case. Instead, to consider a diagnosis, a certain combination and number of symptoms, fewer than the entire number of symptoms of the disorder, must be identified. The second, means that all mental disorders are binary (either/or) concepts. Hence, a disorder is considered to exist when the right combination and number of symptoms can be observed, and absent when such symptoms are not present in the correct number and combination. No exceptions or degrees of variation between existent vs. absent, are considered or permitted (Krueger \& Bezdjian, 2009).

Research evidence indicates that multiple disorders are, in fact, "sequentially comorbid, recurrent/chronic, and exist on a continuum" (Caspi et al., 2014: p. 119). In fact, "predictors of psychological distress syndromes are most accurately operationalized by using dimensional measures" (Kessler, 2002: p. 171). DSM-5 field trials, for example, unveiled that almost $40 \%$ of diagnoses investigated did not reach the acceptable cutoff for inter-rater agreement (Regier et al., 2013). Despite the DSM-5 taking a slightly more dimensional approach, its essence is still categorical hence, as highlighted earlier, it conceptualizes disorders as discrete units-an individual either has it or not (van Heugten-van der Kloet \& van Heugten, 2015).

\subsection{Lack of Diagnostic Precision}

The issues highlighted above are particularly relevant when diagnosing personality disorders (Trull \& Durrett, 2005; Zimmerman, 2011). As noted by Andión et al. (2013), in diagnosing Borderline Personality Disorder (BPD), for example, the DSM-5 system comprises nine diagnostic criteria of which a minimum of five need to be present for its diagnosis. Performing this algorithmic combination yields 256 distinct presentations of BPD. Another example is attempting to capture the range of symptoms for Post-traumatic Stress Disorder (PTSD) which, following the DSM-5 revision, yields the phenomenal number of 636,120 combinations (Galatzer-Levy \& Bryant, 2013).

Three additional examples of problems associated with using a categorical system, such as the DSM-5, to assess and classify personality disorders include the facts that the system: 1) By and large, was generated mostly from research using normal populations and has not been easy to apply to psychopathological populations; 2) Adopted a categorical classification more suitable with the medical classification of diseases; and 3) Experienced controversy (e.g. lack of consensus) relating to proposed recent changes to the classification of personality disorders in DSM-5 (Oldham, 2015). 


\subsection{Subjective, Reductionist, and Atheoretical Approach}

The DSM system, as a representative example, is a codified system that uses a phenomenological approach based on expert consensus (Gogoi, 2017). This subjective, reductionist, and atheoretical approach (lacking psychological or psychiatric theory) relating to etiology (Pilgrim \& Rogers, 2005), takes a biological perspective to the mind, which dismisses advances from neurobiological and sociocultural perspectives, and their contributions, to the science of the mind (Castiglioni \& Laudisa, 2015). As a result, the DSM system poses widely acknowledged short-comings to understanding the true nature and sources of psychopathology, including low symptom specificity, prevalent comorbidity, pronounced diagnostic heterogeneity, and poor reliability (Clark et al., 2017; Krueger et al., 2018; Regier et al., 2013). Not surprisingly, "the biomedical model era has been characterized by a broad lack of clinical innovation and poor mental health outcomes" (Deacon, 2013: p. 846), and lack of clinical utility (Bakker, 2019).

\subsection{Pathologization of Normality}

Another salient controversial change incorporated in the DSM-5 revision relates to the elimination of the "bereavement exclusion clause" contained in the DSM-IV, which dismisses the fact that depressive symptoms can be normal during recent bereavement (Wakefield \& First, 2012). This also exemplifies the social and cultural construction of depression (Bulut, 2019; Kleftaras \& Psarra, 2012), and illustrates how diagnoses can have significant professional, social, economic, and political consequences (Horwitz, 2011). These examples illustrate the inherent flaws and clinical limitations of the DSM-5 classification method, and make its diagnostic validity highly questionable.

\subsection{Self-Stigma, Labelling, and the "Big Pharma"}

A further set of criticisms of categorical systems relates to what some authors (Ben-Zeev et al., 2010; Corrigan \& Watson, 2002) refer to as the "paradox of self-stigma" by noting the negative implications of public stigma, self-stigma, and label avoidance resulting from using dimensional approaches to nosology such as the DSM (e.g. decreased self-efficacy and self-esteem resulting from believing the many stereotypes associated with mental illness), and urges clinicians to educate their clients and the public about the risk of labelling. This is in line with Frances (2013a), who chaired the task force that produced DSM-IV and has been openly critical of the current DSM-5 by referring to the DSM as "the bible of psychiatry; the go-to place to find out who is sick and who is not", and playing "into the hands of 'Big Pharma', who are reaping multi-billion-dollar profits" (p. 14). According to Frances (2013b), "the extensive research has had no effect on psychiatric diagnosis, which still relies exclusively on fallible subjective judgments rather than objective biological tests ... Psychiatric diagnosis is facing a renewed crisis of confidence caused by diagnostic inflation" (p. 221). In a similar 
vein, Greenberg (2013) asserts that psychiatric labels serve the interests of certain clinicians and their professional associations, and the pharmaceutical industry. Within this context, Gøtzsche (2013) compares the global pharmaceutical industry to the mob and claims that politicians, which are heavily lobbied by the industry, do nothing about it. Moreover, Carpenter (2000) alludes to Ritzer's (1996) analogy of the DSM system attempting to standardize normality and mental disorders which is evocative of a "McDonalization" US-flavor of economic and social life. Moynihan et al. (2002) use the expression of "disease mongering" (p. 886) to describe the dangers of inappropriate medicalization of ordinary conditions via pharmaceutical marketing by promoting "breakthrough" medications, and claim that "A lot of money can be made from healthy people who believe they are sick" (p. 886). Such distortions about mental illness are often reinforced by governments that promote depression literacy by emphasizing the biomedical narrative of depression (Gattuso et al., 2005), or fund educational campaigns aimed at beating depression (Pilgrim \& Rogers, 2005).

Based on the foregoing discussion, it is not surprising that growing attention has been focused on the transparency and potential conflicts of interest of biomedical sciences and clinical medicine, along with recommendations of full disclosure by DSM panel members of their financial interests in the manufacture of drugs aimed at treating mental illness (Cosgrove et al., 2006).

In sum, categorical approaches such as the DSM, "have evolved into self-perpetuating systems that now govern and define all aspects of how we conceptualize mental health" (Dalgleish et al., 2020: p. 180), and, like a double-edged sword, have also created "epistemic blinders that impede progress toward valid diagnoses" (Hyman, 2010: p. 155). While some support exists for the reliability of the DSM taxonomy, there are serious questions relating to its validity, utility, and ethics, including sociopolitical and financial agendas (Khoury et al., 2014). As an alternative to categorical systems, a dimensional and hierarchical model to classify psychopathology has been proposed.

\section{The Hierarchical Taxonomy of Psychopathology and the "p" Factor}

Empirical evidence gathered from both child and adult psychiatry, strongly suggests that a single dimension of general psychopathology can measure an individual's susceptibility to mental disorders, comorbidity among disorders, disorder persistence across time, and symptom severity. This single dimension compares conceptually to the "g" factor of general intelligence widely accepted among behavioral scientists, psychologists, and clinicians. Hence, it has been labeled the "general factor of psychopathology" or the "p" factor (Caspi \& Moffitt, 2018). Dimensional models of psychopathology are becoming increasingly popular in mental health research. This has been a response to better reflect symptoms that cut across or transcend the boundaries offered by traditional diagnostic categories, and comorbidity among mental psychopathology (Longenecker et al., 2020). This new dimensional system offers a superior approach to mental 
health compared to traditional and dominant categorical diagnostic approaches such as those codified in the DSM and ICD systems (Conway et al., 2019). Neurobiological research appears to offer the panacea to such problems by focusing on isolated groupings of symptoms or functional constructs, as opposed to categorical diagnoses (Zald \& Lahey, 2017). This approach uses a hierarchy of empirically defined factors of symptoms (e.g. internalizing and externalizing disorders) and the general factor of psychopathology (Lahey et al., 2017). Arguably, the Hierarchical Taxonomy of Psychopathology (HiTOP) model is the most influential thus far (Longenecker et al., 2020).

The HiTOP system is a dimensional alternative to traditional nosologies that was developed by Kotov et al. (2017). The HiTOP system is a data-driven and hierarchically based dimensional classification system of psychopathology along a set of dimensions organized into a broad transdiagnostic array (Ruggero et al., 2019). Based on empirical patterns of comorbidity or psychological symptom co-occurrence, the HiTOP system reflects the state-of-the art in scientific discoveries. The system was developed using the Dunedin Multidisciplinary Health and Development Study (Poulton et al., 2015) by investigating the structure of psychopathology, considering the dimensionality, persistence, co-occurrence, and sequential comorbidity of mental disorders, from adolescence to midlife, across 20 years (Caspi et al., 2014).

\section{Benefits and Advantages}

Three major benefits of using a dimensional system of psychopathology and personality, as opposed to a categorical system, include: 1) Greater measurement precision (Huprich, 2015); 2) Less ambiguity related to a valid construct (Widiger, 2012); and 3) Broader thinking by clinicians about their clients by considering the severity and constellation of specific symptoms among personality disorders (Hopwood, 2011). An example that illustrates the advantages of using dimensional diagnoses in research and clinical practice is the study conducted by Bjelland et al. (2009). This study compared a dimensional and a categorical approach to diagnosis by focusing on co-occurring symptoms of depression and anxiety. The dimensional approach yielded greater power to predict impairment than the categorical one.

Finally, further support for using the "p" factor, relates to how researchers highlight that cognitive processing, attachment, interpersonal, psychodynamic, and evolutionary approaches have strikingly similar ways to conceptualize and treat personality disorders (Huprich, 2015). Based on the above, the HiTOP system offers an evidence-based alternative to traditional categorical diagnostic classification approaches, and a promising future for research and practice of integrative psychotherapy (Hopwood et al., 2019). This relates directly to clinical practice.

\section{Four Examples from the Field}

From a scientist-practitioner perspective, four examples support the foregoing 
discussion of favoring a common factor of psychopathology, and transtherapeutic approaches to clinical practice. The first example relates to the assessment of psychopathology, and the other three exemplify transdiagnostic treatment.

\subsection{Assessment of Psychopathology}

The first example relates to the widespread use among practitioners to assess psychopathology using the Depression Anxiety Stress Scale (DASS) (Lovibond \& Lovibond, 1995). Emotional symptoms such as depression and anxiety are fundamentally dimensional, and fluctuate along a severity continuum, independent of the specific diagnosis (Ronk et al., 2013). Conceptually, the DASS is based on a tripartite model that proposes the disorder of affect (along with its subtypes) exists within a continuum between depression, anxiety and stress, and measures a common factor of negative affectivity (Tully et al., 2009). This means that comorbidities between depression and anxiety are highly prevalent. In fact, about $85 \%$ of individuals presenting with depression symptoms also display significant symptoms of anxiety. Likewise, depression symptoms are observed in up to $90 \%$ of clients with anxiety (Gorman, 1996). The DASS has been found to be a reliable and valid measure of the constructs it purports to measure (Crawford \& Henry, 2003), and can be used as an outcome measure to improve the quality of health care provided by practitioners (Sinclair et al., 2012).

\subsection{Transdiagnostic Treatment of Psychopathology}

The second example relates to how mindfulness "has become a mainstream methodology in mental health treatment" (Jennings et al., 2013: p. 17). Mindfulness is "the awareness that emerges through paying attention, on purpose, in the present moment and nonjudgmentally to the unfolding of the experience moment by moment" (Kabat-Zinn, 2003: p. 145). It involves the self-regulation of the focus of attention to the immediate experience (awareness) without judgement, but rather with openness, curiosity and acceptance as an antidote against most psychological distress (Hayes \& Feldman, 2004). "Recent advances in psychological science, neuroscience, and mindfulness research suggest that mindfulness training can target a variety of mindless mental processes that cut across numerous psychological disorders" (Greeson et al., 2014: p. 534). Like emotion regulation (Sloan et al., 2017), mindfulness has been accepted as a "transdiagnostic treatment of emotional disorders and neuroticism" (Brake et al., 2016: p. 236). This is because most psychopathology entails problems related to lack of insight, inflexibility or holding a narrowed perspective, which is the essence of mindfulness (Greeson et al., 2014). Mindfulness-Based Stress Reduction (MBSR), for example, is known to improve anxiety, depression, and transdiagnostic symptoms linked to stress-related disorders, such as insomnia and various physical symptoms (Greeson et al., 2018).

The third example is the existing strong evidence supporting the efficacy of transdiagnostic CBT, compared to gold-standard diagnosis-specific CBT, for the 
treatment of various types of anxiety disorders (e.g. social anxiety, generalized anxiety, and panic disorder) (Norton \& Barrera, 2012). The Unified Protocol for transdiagnostic treatment of emotional disorders, for example, has been proven to be a practical and cost-effective approach that yields results with heterogeneous anxiety and comorbid depressive disorders with less attrition rates (Barlow et al., 2017; Steele et al., 2018).

The final example in support of adopting a transdiagnostic approach to treatment relates to the treatment principles common to most psychotherapeutic traditions. In recent times, the use of Schema Therapy (ST) or Schema-Focused Cognitive Therapy (Young et al., 2006), has become increasingly popular among psychotherapists as a preferred model for the treatment of their clients (Masley et al., 2012). ST is a relatively new integrative psychotherapy model that was spawned from Beck's (1976) cognitive therapy and progressively culminated into a unique integrative treatment for a spectrum of emotional and relational problems, including personality disorders. ST has now been recognized as an effective and pragmatic type of psychotherapy that integrates previously existing therapies such as Cognitive Behavioral Therapy, Attachment Theory, Psychoanalytic Object Relations, Self-psychology, Relational Psychoanalysis, Social Constructivism, and Gestalt Therapy (Rafaeli et al., 2014).

The developments outlined above relating to the conceptualization, assessment and diagnosis of psychopathology, and to clinical practice, converge with developments in transdiagnostic prevention.

\section{Transdiagnostic Prevention}

A development in the research of prevention programs relates to their classification. The traditional classification of primary, secondary, and tertiary preventions (Dozois \& Dobson, 2004), has been replaced in recent years by a more contemporary classification by recognizing that prevention needed a paradigm shift (O'Connell et al., 2009). This new classification is consistent with Haggerty and Mrazek's (1994) three types of prevention: 1) "universal" (aimed at the general public or populations not identified as being at risk); 2) "selective" (aimed at subgroups identified with significantly higher than average risk of developing the conditions); and 3) "indicated" (aimed at high-risk individuals with identifiable symptoms of the disorders).

The prevention of depression or anxiety, for example, has traditionally been developed in isolation by considering both constructs as independent. As discussed earlier, in reality, these conditions often co-occur and share the same risk and vulnerability factors (e.g. parental psychopathology and parenting; negative cognitions; behavioral inhibition and avoidance, and stress and coping mechanisms). Despite the fact that many of these factors are addressed through existing prevention programs, some risk factors are not regularly targeted. By taking a transdiagnostic approach to prevention (that is, understanding and targeting modifiable vulnerability factors that cut across these two conditions), the efficacy, generalizability, and cost-effectiveness of preventive interventions can be 
improved (Dozois et al., 2009; Topper et al., 2010). A good example of this is how Affect Regulation Training (ART) corrects deficits in emotion regulation that contribute to the development and maintenance of psychopathology (e.g. depression, anxiety, and eating disorders), as an effective transdiagnostic intervention for the prevention and treatment of any type of psychopathology (Berking \& Lukas, 2015; Berking et al., 2019).

\subsection{Rationale and Benefits}

There are six reasons, and their corresponding benefits, for adopting universal transdiagnostic prevention of anxiety and depression, and other forms of psychopathology. Firstly, as noted by Ahlen et al. (2015), universal strategies are a robust means to address widespread problems, with a main advantage compared to targeted interventions, given that the knowledge and means for screening for anxiety and depression disorders within the general population are very limited.

The second reason relates to the distinction between risk and vulnerability. As highlighted by Ingram et al. (2004), risk factors relate to the variables associated with the increased odds of experiencing the disorders. Knowing the risk factors, therefore, provides insight into which individuals or groups should be targeted by prevention initiatives. Vulnerability factors, on the other hand, are the causal mechanisms of the disorders. A good example is gender differences in depression. While knowing that females are at higher risk of anxiety and depression, such information, does not-in itself-explain the mechanisms or processes contributing to anxiety or depression. Therefore, effective prevention requires identification and amelioration of vulnerability factors. In other words, successful prevention should focus on the "what", as opposed to the "who" only.

Thirdly, despite the research evidence indicating high levels of comorbidity between anxiety and depression (Kessler et al., 2005; Adams et al., 2016), many preventive interventions are still designed independently by focusing on depression or anxiety as separate and independent constructs. As a result, very few studies have investigated preventive interventions targeting simultaneously both symptom clusters (Topper et al., 2017). This deficiency is addressed by adopting a transdiagnostic prevention approach.

The fourth reason for focusing on universal prevention is that much of the previous research has confused prevention and treatment, thus citing effect sizes in selective or indicated samples as evidence for preventive efficacy, disregarding the trajectory of healthy participants over time. Adolescence is a period of development defined by vulnerability to psychopathology (Nehmy \& Wade, 2015).

The fifth reason is that adopting universal preventions, as part of the school curriculum, for example, reduces the costs associated with the prevention (Barrett \& Pahl, 2006). The sixth and final reason for, and benefit of, focusing on universal preventions is that they better address the stigma associated with mental illness. Mental illness stigma comprises stereotypes, prejudice and discrimination, and is an important reason for individuals not seeking effective treatment and care (Corrigan et al., 2014). 
The developments outlined thus far in HiTOP and transdiagnostic treatment, have important implications for the general prevention, assessment, and diagnosis of psychopathology. Their integration provides a robust strategic prevention framework to reduce early psychopathology.

\subsection{Prevention of Mental Health by Reducing Early Psychopathology}

Forbes et al. (2019) recently proposed a developmental and transdiagnostic approach to minimize general psychopathology during formative years while building the foundation for the prevention and treatment of successive psychopathology. Consistent with this, and taking into account that only $10 \%$ of psychopathology originates at the age of 5 (Cía et al., 2018), the framework scaffolds interventions from early age. For example, "authoritative" parenting (characterized by reasonable demands and high responsiveness to the child's emotional needs, while having high standards and setting clear limits), when compared to "authoritarian" parenting (e.g. exceedingly high expectations with little warmth and guidance), predicts competent and well-adjusted adolescents (Baumrind et al., 2010). The framework is also consistent with Haggerty and Mrazek's (1994) view that the separation between prevention and treatment is unnecessary, as they exist within a continuum depending on the progression of the psychopathology. From this perspective, universal interventions are at one end of the continuum, and long-term care is at the other end. Selective interventions, then, complement universal interventions by focusing on children who display high levels of known risks for general psychopathology. The framework comprises four clusters or components. Each cluster maps each level of the hierarchical structure of psychopathology to its corresponding stage of human development from early childhood to adulthood.

The next section explains how the links between transdiagnostic prevention, and advancements in neuroscience and modern attachment theory, enable the development of attachment-based prevention programs early in life to achieve positive long-term developmental outcomes.

\section{Modern Attachment Theory and the First Thousand Days}

Modern attachment theory (MAT) builds on Bowlby's (1958) attachment theory, later expanded by Ainsworth (1968), which postulates that attachment results from the emotional, relational, and brain development processes by which humans learn to relate to the self, to others, and the world around them. MAT rests on three basic principles: 1) emotional bonding is an inherent human need; 2) emotional regulation enhances vitality; and 3) emotions and attachment behaviors promote growth and adaptiveness (Schore \& Schore, 2008). This represents a paradigm shift from the "cognitive revolution" of the mid-1960s, which had defied behaviorism and led to the development of cognitive science, to various new models of attachment. This fundamental change became noticeable via at least two converging themes. First, psychology and neuroscience shifted their 
focus from cognition to emotion (Schore \& Newton, 2013). Second, neurobiological development expanded significantly (Schore, 2015). As Ryan (2007) puts it, " ... after three decades of the dominance of cognitive approaches, motivational and emotional processes have roared back into the limelight" (p. 1). MAT has undergone exceptional expansion in the last decade, both theoretically and in applied clinical work. Such advances offer compelling evidence for considering mental health prevention in a fully integrated fashion. This has included the integration of biological and psychological models of human development, and neuroscience. Namely, developments in interactive emotional regulation, affective bodily-based processes, early experience-dependent brain maturation, and nonconscious relational transactions (Schore \& Newton, 2013).

As a result, "These studies have also changed how we view psychopathology. Most mental illnesses, for example, begin far earlier in life than was previously believed" (Insel \& Fenton, 2005: p. 590). It is now clear that life in utero, the immediate postnatal environment, and the child and caregivers' relations within the first years of life, have enduring impact on the child's brain development and behavior. Hence, the scientific consensus is that "... the origins of adult disease are often found among developmental and biological disruptions occurring during the early years of life" (Leckman \& March, 2011: p. 333). Such early life experiences can affect mental health in adulthood in two different ways: by embedding adversities biologically during critically sensitive developmental periods; or by causing cumulative damage over time. In each case, years or decades can pass before early adverse experiences are expressed pathologically. Therefore, identifying the origins of psychopathology in early life is far more likely to have greater effects than trying to modify mental health-related problems in adulthood (Shonkoff et al., 2009). Shonkoff et al. (2011), for example, state that "interventions that enhance the mental health, executive function skills, and self-regulation capacities of vulnerable mothers, beginning as early as pregnancy, suggest promising strategies to protect the developing brains of their children" (p. 983). These findings, which include the impact and the long-term effects of early experiences and exposures, have been referred to as the factors that affect development during "the first 1000 days" from the period of conception to the end of the second year (Moore et al., 2017).

\section{Practical Implications}

The utilities of using a transdiagnostic stepped approach to mental health are severalfold.

First, it clarifies the existing confusion for the general public-and parents in particular-to choose from the myriad of different programs available to reduce anxiety, depression, eating psychopathology, aggressive behaviors, and substance abuse (Werner-Seidler et al., 2017). It also enables consistent funding guidelines from healthcare and community education systems (Forbes et al., 2019). Next, by focusing on shared common risks across psychopathology and taking a stepped-care approach, as opposed to focusing on single disorders (e.g. anxiety 
or depression), this approach is more likely to have a greater positive impact for most individuals, without excluding people who have more complex needs (Cross \& Hickie, 2017). Third, reducing general psychopathology risks in early life would be likely to trigger a wide chain of positive benefits developmentally through the cumulative consequences for development or "developmental cascades" (Okano et al., 2019). For example, early childhood programs that facilitate emotional regulation and lower impulsivity are very likely to enable effective social skills and positive peer relationships in middle childhood, which, in turn, support commitment and academic performance during adolescence in high school, and sequentially reduce the risk of psychopathology during adulthood. I can attest from professional experience that clinicians witness the impact of this chain in their everyday work. Moreover, early childhood programs circumvent the challenge that for prevention and change interventions to be successful later in life, motivation and readiness for change is required (Prochaska \& DiClemente, 1983) and hence such later interventions need to target participants' motivation (Dozois, 2004). Finally, adopting a developmental approach maximizes the efficiency of interventions because, as highlighted earlier, psychopathology emerges at an early age (Cía et al., 2018).

\section{Limitations}

This conceptual paper is limited to literature, prior empirical research, and lessons from the field. Despite this limitation, the paper is original, synthesizes the extant literature and empirical findings, bridges existing theories in new ways, links practices across disciplines, provides multi-level insights, and broadens the scope of the prevailing thinking for a better understanding of the prevention, assessment, diagnosis and treatment of mental health, and the practice of psychotherapy.

\section{Conclusion}

Informed by the recently developed HiTOP system, the latest developments in the areas of transdiagnostic prevention and treatment, modern attachment theory, and insights from clinical practice, this paper has presented a new transdiagnostic developmentally based approach for the prevention, assessment, diagnosis, and treatment of psychopathology, as an alternative to keep using the dominant categorical classification systems of mental disorders and the pervasive biomedical model of mental health. This emerging approach comprises a hierarchical structure of psychopathology that deals with shortcomings such as: ambiguous boundaries between disorders; arbitrary boundaries between psychopathology and normality; recurrent disorder co-occurrence; heterogeneity within disorders; and diagnostic inconsistency of traditional taxonomies. It also offers a practical and effective framework for the prevention of mental health from early childhood to adulthood. The paper has synthesized and integrated relevant theoretical advancements, concepts, and expectations that 
inform, guide, and support future research and practice in the area of prevention and treatment of mental health, which are worthy of consideration.

\section{Conflicts of Interest}

The author declares no conflicts of interest regarding the publication of this paper.

\section{References}

Adams, G. C., Balbuena, L., Meng, X., \& Asmundson, G. J. (2016). When Social Anxiety and Depression Go Together: A Population Study of Comorbidity and Associated Consequences. Journal of Affective Disorders, 206, 48-54. https://doi.org/10.1016/j.jad.2016.07.031

Ahlen, J., Lenhard, F., \& Ghaderi, A. (2015). Universal Prevention for Anxiety and Depressive Symptoms in Children: A Meta-Analysis of Randomized and Cluster-Randomized Trials. The Journal of Primary Prevention, 36, 387-403. https://doi.org/10.1007/s10935-015-0405-4

Ainsworth, M. D. S. (1968). Object Relations, Dependency, and Attachment: A Theoretical Review of the Infant-Mother Relationship. Child Development, 40, 969-1025. https://www.jstor.org/stable/1127008 https://doi.org/10.2307/1127008

Allsopp, K., Read, J., Corcoran, R., \& Kinderman, P. (2019). Heterogeneity in Psychiatric Diagnostic Classification. Psychiatry Research, 279, 15-22. https://doi.org/10.1016/j.psychres.2019.07.005

Andión, Ó., Ferrer, M., Calvo, N., Gancedo, B., Barral, C., Di Genova, A. et al. (2013). Exploring the Clinical Validity of Borderline Personality Disorder Components. Comprehensive Psychiatry, 54, 34-40. https://doi.org/10.1016/j.comppsych.2012.06.004

Awenat, F., Berger, B., Coles, S., Dooley, C., Foster, S., Hanna, J. et al. (2013). Classification of Behaviour and Experience in Relation to Functional Psychiatric Diagnoses: Time for a Paradigm Shift. Leicester: British Psychological Society.

Bakker, G. M. (2019). A New Conception and Subsequent Taxonomy of Clinical Psychological Problems. BMC Psychology, 7, Article No. 46. https://doi.org/10.1186/s40359-019-0318-8

Barlow, D. H., Farchione, T. J., Bullis, J. R., Gallagher, M. W., Murray-Latin, H., Sauer-Zavala, S. et al. (2017). The Unified Protocol for Transdiagnostic Treatment of Emotional Disorders Compared with Diagnosis-Specific Protocols for Anxiety Disorders: A Randomized Clinical Trial. JAMA Psychiatry, 74, 875-884.

https://doi.org/10.1001/jamapsychiatry.2017.2164

Barrett, P. M., \& Pahl, K. M. (2006). School-Based Intervention: Examining a Universal Approach to Anxiety Management. Journal of Psychologists and Counsellors in Schools, 16, 55-75. https://doi.org/10.1375/ajgc.16.1.55

Baumrind, D., Larzelere, R. E., \& Owens, E. B. (2010). Effects of Preschool Parents' Power Assertive Patterns and Practices on Adolescent Development. Parenting: Science and Practice, 10, 157-201. https://doi.org/10.1080/15295190903290790

Beck, A. T. (1976). Cognitive Therapy and the Emotional Disorders. Madison, CT: International Universities Press.

Bentall, R. P. (2014). Western Models for Mental Health: A Cautionary Note. Commonwealth Health Partnerships, 131-134. 
http://www.commonwealthhealth.org/wp-content/uploads/2014/05/5-Western-models -for-mental-health-bentall.pdf

Ben-Zeev, D., Young, M. A., \& Corrigan, P. W. (2010). DSM-V and the Stigma of Mental Illness. Journal of Mental Health, 19, 318-327. https://doi.org/10.3109/09638237.2010.492484

Berking, M., \& Lukas, C. A. (2015). The Affect Regulation Training (ART): A Transdiagnostic Approach to the Prevention and Treatment of Mental Disorders. Current Opinion in Psychology, 3, 64-69. https://doi.org/10.1016/j.copsyc.2015.02.002

Berking, M., Eichler, E., Luhmann, M., Diedrich, A., Hiller, W., \& Rief, W. (2019). Affect Regulation Training Reduces Symptom Severity in Depression-A Randomized Controlled Trial. PLoS ONE, 14, e0220436. https://doi.org/10.1371/journal.pone.0220436

Bjelland, I., Lie, S. A., Dahl, A. A., Mykletun, A., Stordal, E., \& Kraemer, H. C. (2009). A Dimensional versus a Categorical Approach to Diagnosis: Anxiety and Depression in the HUNT 2 Study. International Journal of Methods in Psychiatric Research, 18, 128-137. https://doi.org/10.1002/mpr.284

Bowlby, J. (1958). The Nature of the Child's Tie to His Mother. The International Journal of Psychoanalysis, 39, 350-373. https://psycnet.apa.org/record/1960-02815-001

Brake, C. A., Sauer-Zavala, S., Boswell, J. F., Gallagher, M. W., Farchione, T. J., \& Barlow, D. H. (2016). Mindfulness-Based Exposure Strategies as a Transdiagnostic Mechanism of Change: An Exploratory Alternating Treatment Design. Behavior Therapy, 47, 225-238. https://doi.org/10.1016/j.beth.2015.10.008

Bulut, S. (2019). Socialization Helps the Treatment of Depression in Modern Life. Open Journal of Depression, 8, 41-47. https://doi.org/10.4236/ojd.2019.82005

Carpenter, M. (2000). “It's a Small World”: Mental Health Policy under Welfare Capitalism Since 1945. Sociology of Health \& Illness, 22, 602-620. https://doi.org/10.1111/1467-9566.00222

Caspi, A., \& Moffitt, T. E. (2018). All for One and One for All: Mental Disorders in One Dimension. American Journal of Psychiatry, 175, 831-844.

https://doi.org/10.1176/appi.ajp.2018.17121383

Caspi, A., Houts, R. M., Belsky, D. W., Goldman-Mellor, S. J., Harrington, H., Israel, S. et al. (2014). The p Factor: One General Psychopathology Factor in the Structure of Psychiatric Disorders? Clinical Psychological Science, 2, 119-137. https://doi.org/10.1177/2167702613497473

Castiglioni, M., \& Laudisa, F. (2015). Toward Psychiatry as a "Human" Science of Mind. The Case of Depressive Disorders in DSM-5. Frontiers in Psychology, 5, 1517. https://doi.org/10.3389/fpsyg.2014.01517

Cía, A. H., Stagnaro, J. C., Gaxiola, S. A., Vommaro, H., Loera, G., Medina-Mora, M. E. et al. (2018). Lifetime Prevalence and Age-of-Onset of Mental Disorders in Adults from the Argentinean Study of Mental Health Epidemiology. Social Psychiatry and Psychiatric Epidemiology, 53, 341-350. https://doi.org/10.1007/s00127-018-1492-3

Clark, L. A., Cuthbert, B., Lewis-Fernández, R., Narrow, W. E., \& Reed, G. M. (2017). Three Approaches to Understanding and Classifying Mental Disorder: ICD-11, DSM-5, and the National Institute of Mental Health's Research Domain Criteria (RDoC). Psychological Science in the Public Interest, 18, 72-145. https://doi.org/10.1177/1529100617727266

Conway, C. C., Forbes, M. K., Forbush, K. T., Fried, E. I., Hallquist, M. N., Kotov, R. et al. (2019). A Hierarchical Taxonomy of Psychopathology Can Transform Mental Health Research. Perspectives on Psychological Science, 14, 419-436. 
https://doi.org/10.1177/1745691618810696

Corrigan, P. W., \& Watson, A. C. (2002). The Paradox of Self-Stigma and Mental Illness. Clinical Psychology: Science and Practice, 9, 35-53.

https://doi.org/10.1093/clipsy.9.1.35

Corrigan, P. W., Druss, B. G., \& Perlick, D. A. (2014). The Impact of Mental Illness Stigma on Seeking and Participating in Mental Health Care. Psychological Science in the Public Interest, 15, 37-70. https://doi.org/10.1177/1529100614531398

Cosgrove, L., Krimsky, S., Vijayaraghavan, M., \& Schneider, L. (2006). Financial Ties between DSM-IV Panel Members and the Pharmaceutical Industry. Psychotherapy and Psychosomatics, 75, 154-160. https://doi.org/10.1159/000091772

Crawford, J. R., \& Henry, J. D. (2003). The Depression Anxiety Stress Scales (DASS): Normative Data and Latent Structure in a Large Non-Clinical Sample. British Journal of Clinical Psychology, 42, 111-131.

Cross, S. P., \& Hickie, I. (2017). Transdiagnostic Stepped Care in Mental Health. Public Health Research and Practice, 27, e2721712. https://doi.org/10.17061/phrp2721712

Dalgleish, T., Black, M., Johnston, D., \& Bevan, A. (2020). Transdiagnostic Approaches to Mental Health Problems: Current Status and Future Directions. Journal of Consulting and Clinical Psychology, 88, 179-195. https://doi.org/10.1037/ccp0000482

Deacon, B. J. (2013). The Biomedical Model of Mental Disorder: A Critical Analysis of Its Validity, Utility, and Effects on Psychotherapy Research. Clinical Psychology Review, 33, 846-861. https://doi.org/10.1016/j.cpr.2012.09.007

Dozois, D. J. (2004). Prevention of Anxiety Psychopathology: Conceptual, Methodological, and Practical Issues. Clinical Psychology: Science and Practice, 11, 425-429. https://doi.org/10.1093/clipsy.bph099

Dozois, D. J., \& Dobson, K. S. (2004). The Prevention of Anxiety and Depression: Theory, Research, and Practice. Washington DC: American Psychological Association. https://doi.org/10.1037/10722-000

Dozois, D. J., Seeds, P. M., \& Collins, K. A. (2009). Transdiagnostic Approaches to the Prevention of Depression and Anxiety. Journal of Cognitive Psychotherapy, 23, 44-59. https://doi.org/10.1891/0889-8391.23.1.44

Forbes, M. K., Rapee, R. M., \& Krueger, R. F. (2019). Opportunities for the Prevention of Mental Disorders by Reducing General Psychopathology in Early Childhood. Behaviour Research and Therapy, 119, Article ID: 103411.

https://doi.org/10.1016/j.brat.2019.103411

Frances, A. (2013a). Saving Normal: An Insider's Revolt against Out-of-Control Psychiatric Diagnosis, DSM-5, Big Pharma and the Medicalization of Ordinary Life. Psychotherapy in Australia, 19, 14-18.

https://search.informit.com.au/documentSummary; $\mathrm{dn}=464019439257830 ;$;res=IELHEA

Frances, A. (2013b). The New Crisis of Confidence in Psychiatric Diagnosis. Annals of Internal Medicine, 159, 221-223. https://europepmc.org/article/med/23685989

Galatzer-Levy, I. R., \& Bryant, R. A. (2013). 636,120 Ways to Have Posttraumatic Stress Disorder. Perspectives on Psychological Science, 8, 651-662.

https://doi.org/10.1177/1745691613504115

Gattuso, S., Fullagar, S., \& Young, I. (2005). Speaking of Women's “Nameless Misery”: The Everyday Construction of Depression in Australian Women's Magazines. Social Science \& Medicine, 61, 1640-1648. https://doi.org/10.1016/j.socscimed.2005.03.020

Gogoi, D. (2017). Fundamental Concepts of Phenomenology and Descriptive Psychopathology. Open Journal of Psychiatry \& Allied Sciences, 8, 11-14. 
https://www.ojpas.com/phenomenologyandpsychopathologyfulltext.html https://doi.org/10.5958/2394-2061.2016.00039.2

Goldacre, B. (2014). Bad Pharma: How Drug Companies Mislead Doctors and Harm Patients. Macmillan.

Gorman, J. M. (1996). Comorbid Depression and Anxiety Spectrum Disorders. Depression and Anxiety, 4, 160-168. https://doi.org/10.1002/(SICI)1520-6394(1996)4:4<160::AID-DA2>3.0.CO;2-J

Gøtzsche, P. (2013). Deadly Medicines and Organised Crime: How Big Pharma Has Corrupted Healthcare. London: Radcliffe.

Greenberg, G. (2013). The Book of Woe: The DSM and the Unmaking of Psychiatry. Penguin.

Greeson, J. M., Zarrin, H., Smoski, M. J., Brantley, J. G., Lynch, T. R., Webber, D. M. et al. (2018). Mindfulness Meditation Targets Transdiagnostic Symptoms Implicated in Stress-Related Disorders: Understanding Relationships between Changes in Mindfulness, Sleep Quality, and Physical Symptoms. Evidence-Based Complementary and Alternative Medicine, 2018, Article ID: 4505191. https://doi.org/10.1155/2018/4505191

Greeson, J., Garland, E. L., \& Black, D. (2014). Mindfulness: A Transtherapeutic Approach for Transdiagnostic Mental Processes. In A. le, C. T. Ngnoumen, \& E. J. Langer (Eds.), The Wiley Blackwell Handbook of Mindfulness (pp. 533-562). Hoboken, NJ: Wiley-Blackwell. https://doi.org/10.1002/9781118294895.ch28

Guerin, B. (2017). How to Rethink Mental Illness: The Human Contexts behind the Labels. Milton Park, Abingdon-on-Thames: Taylor \& Francis. https://doi.org/10.4324/9781315462615

Haggerty, R. J., \& Mrazek, P. J. (Eds.) (1994). Reducing Risks for Mental Disorders: Frontiers for Preventive Intervention Research. Washington DC: National Academies Press.

Hayes, A. M., \& Feldman, G. (2004). Clarifying the Construct of Mindfulness in the Context of Emotion Regulation and the Process of Change in Therapy. Clinical Psychology: Science and Practice, 11, 255-262. https://doi.org/10.1093/clipsy.bph080

Hengartner, M. P., \& Lehmann, S. N. (2017). Why Psychiatric Research Must Abandon Traditional Diagnostic Classification and Adopt a Fully Dimensional Scope: Two Solutions to a Persistent Problem. Frontiers in Psychiatry, 8, 101.

https://doi.org/10.3389/fpsyt.2017.00101

Hopwood, C. J. (2011). Personality Traits in the DSM-5. Journal of Personality Assessment, 93, 398-405. https://doi.org/10.1080/00223891.2011.577472

Hopwood, C. J., Bagby, R. M., Gralnick, T., Ro, E., Ruggero, C., Mullins-Sweatt, S., Kotov, R., Bach, B., Cicero, D. C., Krueger, R. F., Patrick, C. J., Chmielewski, M., DeYoung, C. G., Docherty, A. R., Eaton, N. R., Forbush, K. T., Ivanova, M. Y., Latzman, R. D., Pincus, A. L. et al. (2019). Integrating Psychotherapy with the Hierarchical Taxonomy of Psychopathology (HiTOP). Journal of Psychotherapy Integration, advance online publication. https://doi.org/10.1037/int0000156

Horwitz, A. V. (2011). Creating an Age of Depression: The Social Construction and Consequences of the Major Depression Diagnosis. Society and Mental Health, 1, 41-54. https://doi.org/10.1177/2156869310393986

Huprich, S. K. (Ed.) (2015). Personality Disorders: Toward Theoretical and Empirical Integration in Diagnosis and Assessment. Washington DC: American Psychological Association. https://doi.org/10.1037/14549-000

Hyman, S. E. (2010). The Diagnosis of Mental Disorders: The Problem of Reification. Annual Review of Clinical Psychology, 6, 155-179. 
https://doi.org/10.1146/annurev.clinpsy.3.022806.091532

Ingram, R. E., Odom, M., \& Mitchusson, T. (2004). Secondary Prevention of Depression: Risk, Vulnerability, and Intervention. In D. J. A. Dozois, \& K. S. Dobson (Eds.), The Prevention of Anxiety and Depression: Theory, Research, and Practice (pp. 205-231). Washington DC: American Psychological Association. https://doi.org/10.1037/10722-009

Insel, T. R., \& Fenton, W. S. (2005). Psychiatric Epidemiology: It's Not Just about Counting Anymore. Archives of General Psychiatry, 62, 590-592. https://doi.org/10.1001/archpsyc.62.6.590

Jennings, J. L., Apsche, J. A., Blossom, P., \& Bayles, C. (2013). Using Mindfulness in the Treatment of Adolescent Sexual Abusers: Contributing Common Factor or a Primary Modality? International Journal of Behavioral Consultation and Therapy, 8, 17-22. https://doi.org/10.1037/h0100978

Kabat-Zinn, J. (2003). Mindfulness-Based Interventions in Context: Past, Present, and Future. Clinical Psychology: Science and Practice, 10, 144-156. https://doi.org/10.1093/clipsy.bpg016

Kawa, S., \& Giordano, J. (2012). A Brief Historicity of the Diagnostic and Statistical Manual of Mental Disorders. Issues and Implications for the Future of Psychiatric Canon and Practice. Philosophy, Ethics, and Humanities in Medicine, 7, Article No. 2. https://doi.org/10.1186/1747-5341-7-2

Kessler, R. C. (2002). The Categorical versus Dimensional Assessment Controversy in the Sociology of Mental Illness. Journal of Health and Social Behavior, 43, 171-188. https://www.jstor.org/stable/3090195 https://doi.org/10.2307/3090195

Kessler, R., Chiu, W., Demler, O., \& Walters, E. (2005). Prevalence, Severity, and Comorbidity of 12-Month DSM-IV Disorders in the National Comorbidity Survey Replication. Archives of General Psychiatry, 62, 617-627. https://doi.org/10.1001/archpsyc.62.6.617

Khoury, B., Langer, E. J., \& Pagnini, F. (2014). The DSM: Mindful Science or Mindless Power? A Critical Review. Frontiers in Psychology, 5, 602. https://doi.org/10.3389/fpsyg.2014.00602

Kinderman, P. (2017). A Manifesto for Psychological Health and Wellbeing. In J. Davies, Ed., The Sedated Society (pp. 271-301). Cham: Palgrave Macmillan. https://doi.org/10.1007/978-3-319-44911-1 11

Kleftaras, G., \& Psarra, E. (2012). Meaning in Life, Psychological Well-Being and Depressive Symptomatology: A Comparative Study. Psychology, 3, 337-345.

https://doi.org/10.4236/psych.2012.34048

Kotov, R., Krueger, R. F., Watson, D., Achenbach, T. M., Althoff, R. R., Bagby, R. M., Brown, T. A., Carpenter, W. T., Caspi, A., Clark, L. A., Eaton, N. R., Forbes, M. K., Forbush, K. T., Goldberg, D., Hasin, D., Hyman, S. E., Ivanova, M. Y., Lynam, D. R., Markon, K. et al. (2017). The Hierarchical Taxonomy of Psychopathology (HiTOP): A Dimensional Alternative to Traditional Nosologies. Journal of Abnormal Psychology, 126, 454-477. https://doi.org/10.1037/abn0000258

Krueger, R. F., Kotov, R., Watson, D., Forbes, M. K., Eaton, N. R., Ruggero, C. J. et al. (2018). Progress in Achieving Quantitative Classification of Psychopathology. World Psychiatry, 17, 282-293. https://doi.org/10.1002/wps.20566

Lahey, B. B., Krueger, R. F., Rathouz, P. J., Waldman, I. D., \& Zald, D. H. (2017). A Hierarchical Causal Taxonomy of Psychopathology across the Life Span. Psychological Bulletin, 143, 142-186. https://doi.org/10.1037/bul0000069 
Leckman, J. F., \& March, J. S. (2011). Editorial: Developmental Neuroscience Comes of Age. Journal of Child Psychology and Psychiatry, 52, 333-338. https://doi.org/10.1111/j.1469-7610.2011.02378.x

Longenecker, J. M., Krueger, R. F., \& Sponheim, S. R. (2020). Personality Traits across the Psychosis Spectrum: A Hierarchical Taxonomy of Psychopathology Conceptualization of Clinical Symptomatology. Personality and Mental Health, 14, 88-105. https://doi.org/10.1002/pmh.1448

Lovibond, P. F., \& Lovibond, S. H. (1995). The Structure of Negative Emotional States: Comparison of the Depression Anxiety Stress Scales (DASS) with the Beck Depression and Anxiety Inventories. Behaviour Research and Therapy, 33, 335-343. https://doi.org/10.1016/0005-7967(94)00075-U

Masley, S. A., Gillanders, D. T., Simpson, S. G., \& Taylor, M. A. (2012). A Systematic Review of the Evidence Base for Schema Therapy. Cognitive Behaviour Therapy, 41, 185-202. https://doi.org/10.1080/16506073.2011.614274

Middleton, H. (2015). The Medical Model: What Is It, Where Did It Come from and How Long Has It Got? In D. Loewenthal (Ed.), Critical Psychotherapy, Psychoanalysis and Counselling (pp. 29-40). London: Palgrave Macmillan. https://doi.org/10.1057/9781137460585 2

Moore, T., Arefadib, N., Deery, A., Keyes, M., \& West, S. (2017). The First Thousand Days: An Evidence Paper. Parkville: Murdoch Children's Research Institute. https://www.rch.org.au/uploadedFiles/Main/Content/ccchdev/CCCH-The-First-Thous and-Days-An-Evidence-Paper-September-2017.pdf

Moynihan, R., Heath, I., \& Henry, D. (2002). Selling Sickness: The Pharmaceutical Industry and Disease Mongering. British Medical Journal, 324, 886-891. https://doi.org/10.1136/bmj.324.7342.886

Nehmy, T. J., \& Wade, T. D. (2015). Reducing the Onset of Negative Affect in Adolescents: Evaluation of a Perfectionism Program in a Universal Prevention Setting. Behaviour Research and Therapy, 67, 55-63. https://doi.org/10.1016/j.brat.2015.02.007

Norton, P. J., \& Barrera, T. L. (2012). Transdiagnostic versus Diagnosis-Specific CBT for Anxiety Disorders: A Preliminary Randomized Controlled Noninferiority Trial. Depression and Anxiety, 29, 874-882. https://doi.org/10.1002/da.21974

O’Connell, M. E., Boat, T., \& Warner, K. E. (2009). Preventing Mental, Emotional, and Behavioral Disorders among Young People: Progress and Possibilities (Vol. 7). Washington DC: National Academies Press.

Okano, L., Jeon, L., Crandall, A., Powell, T., \& Riley, A. (2019). Developmental Cascades of Social Competence, Achievement in School, and Achievement on Standardized Assessments during the Transition to Adolescence and Secondary School. Journal of Adolescence, 74, 91-102. https://doi.org/10.1016/j.adolescence.2019.06.001

Oldham J. M. (2015). The Alternative DSM-5 Model for Personality Disorders. World Psychiatry, 14, 234-236. https://doi.org/10.1002/wps.20232

Pemberton, R., \& Wainwright, T. (2014). The End of Mental Illness Thinking? International Journal of Clinical and Health Psychology, 14, 216-220.

https://doi.org/10.1016/j.ijchp.2014.05.003

Pilgrim, D., \& Rogers, A. (2005). The Troubled Relationship between Psychiatry and Sociology. International Journal of Social Psychiatry, 51, 228-241. https://doi.org/10.1177/0020764005056987

Poulton, R., Moffitt, T. E., \& Silva, P. A. (2015). The Dunedin Multidisciplinary Health and Development Study: Overview of the First 40 Years, with an Eye to the Future. So- 
cial Psychiatry and Psychiatric Epidemiology, 50, 679-693.

https://doi.org/10.1007/s00127-015-1048-8

Prochaska, J. O., \& DiClemente, C. C. (1983). Stages and Processes of Self-Change of Smoking: Toward an Integrative Model of Change. Journal of Consulting and Clinical Psychology, 51, 390-395. https://doi.org/10.1037/0022-006X.51.3.390

Rafaeli, E., Maurer, O., \& Thoma, N. C. (2014). Working with Modes in Schema Therapy. Working with Emotion in Cognitive Behavioral Therapy: Techniques for Clinical Practice (pp. 263-287). New York: Guilford Publications.

Regier, D. A., Narrow, W. E., Clarke, D. E., Kraemer, H. C., Kuramoto, S. J., Kuhl, E. A., \& Kupfer, D. J. (2013). DSM-5 Field Trials in the United States and Canada, Part II: Test-Retest Reliability of Selected Categorical Diagnoses. American Journal of Psychiatry, 170, 59-70. https://doi.org/10.1176/appi.ajp.2012.12070999

Ritzer, G. (1996). The McDonaldization Thesis: Is Expansion Inevitable? International Sociology, 11, 291-308. https://doi.org/10.1177/026858096011003002

Ronk, F. R., Korman, J. R., Hooke, G. R., \& Page, A. C. (2013). Assessing Clinical Significance of Treatment Outcomes Using the DASS-21. Psychological Assessment, 25, 1103-1110. https://doi.org/10.1037/a0033100

Ruggero, C. J., Kotov, R., Hopwood, C. J., First, M., Clark, L. A., Skodol, A. E., Mullins-Sweatt, S. N., Patrick, C. J., Bach, B., Cicero, D. C., Docherty, A., Simms, L. J., Bagby, R. M., Krueger, R. F., Callahan, J. L., Chmielewski, M., Conway, C. C., De Clercq, B., Dornbach-Bender, A. et al. (2019). Integrating the Hierarchical Taxonomy of Psychopathology (HiTOP) into Clinical Practice. Journal of Consulting and Clinical Psychology, 87, 1069-1084. https://doi.org/10.1037/ccp0000452

Ryan, R. M. (2007). Motivation and Emotion: A New Look and Approach for Two Reemerging Fields. Motivation and Emotion, 31, 1-3.

https://doi.org/10.1007/s11031-007-9055-Z

Schore, A. N. (2015). Affect Regulation and the Origin of the Self: The Neurobiology of Emotional Development. New York: Routledge. https://doi.org/10.4324/9781315680019

Schore, A. N., \& Newton, R. P. (2013). Using Modern Attachment Theory to Guide Clinical Assessments of Early Attachment Relationships. In J. E. Bettmann, \& D. D. Friedman (Eds.), Attachment-Based Clinical Work with Children and Adolescents (pp. 61-96). Berlin: Springer. https://doi.org/10.1007/978-1-4614-4848-8 4

Schore, J. R., \& Schore, A. N. (2008). Modern Attachment Theory: The Central Role of Affect Regulation in Development and Treatment. Clinical Social Work Journal, 36, 9-20. https://doi.org/10.1007/s10615-007-0111-7

Shonkoff, J. P. (2011). Protecting Brains, Not Simply Stimulating Minds. Science, 333, 982-983. https://doi.org/10.1126/science.1206014

Shonkoff, J. P., Boyce, W. T., \& McEwen, B. S. (2009). Neuroscience, Molecular Biology, and the Childhood Roots of Health Disparities Building a New Framework for Health Promotion and Disease Prevention. Journal of the American Medical Association, 301, 2252-2259. https://doi.org/10.1001/jama.2009.754

Shorter, E. (2015). The History of Nosology and the Rise of the Diagnostic and Statistical Manual of Mental Disorders. Dialogues in Clinical Neuroscience, 17, 59-67. https://www.ncbi.nlm.nih.gov/pmc/articles/PMC4421901/

Sinclair, S. J., Siefert, C. J., Slavin-Mulford, J. M., Stein, M. B., Renna, M., \& Blais, M. A. (2012). Psychometric Evaluation and Normative Data for the Depression, Anxiety, and 
Stress Scales-21 (DASS-21) in a Nonclinical Sample of US Adults. Evaluation \& the Health Professions, 35, 259-279. https://doi.org/10.1177/0163278711424282

Sloan, E., Hall, K., Moulding, R., Bryce, S., Mildred, H., \& Staiger, P. K. (2017). Emotion Regulation as a Transdiagnostic Treatment Construct across Anxiety, Depression, Substance, Eating and Borderline Personality Disorders: A Systematic Review. Clinical Psychology Review, 57, 141-163. https://doi.org/10.1016/j.cpr.2017.09.002

Steele, S. J., Farchione, T. J., Cassiello-Robbins, C., Ametaj, A., Sbi, S., Sauer-Zavala, S., \& Barlow, D. H. (2018). Efficacy of the Unified Protocol for Transdiagnostic Treatment of Comorbid Psychopathology Accompanying Emotional Disorders Compared to Treatments Targeting Single Disorders. Journal of Psychiatric Research, 104, 211-216. https://doi.org/10.1016/i.jpsychires.2018.08.005

Stein, D. J., Lund, C., \& Nesse, R. M. (2013). Classification Systems in Psychiatry: Diagnosis and Global Mental Health in the Era of DSM-5 and ICD-11. Current Opinion in Psychiatry, 26, 493-497. https://doi.org/10.1097/YCO.0b013e3283642dfd

Timimi, S. (2014). No More Psychiatric Labels: Why Formal Psychiatric Diagnostic Systems Should Be Abolished. International Journal of Clinical and Health Psychology, 14, 208-215. https://doi.org/10.1016/j.ijchp.2014.03.004

Topper, M., Emmelkamp, P. M., \& Ehring, T. (2010). Improving Prevention of Depression and Anxiety Disorders: Repetitive Negative Thinking as a Promising Target. Applied and Preventive Psychology, 14, 57-71. https://doi.org/10.1016/j.appsy.2012.03.001

Topper, M., Emmelkamp, P. M., Watkins, E., \& Ehring, T. (2017). Prevention of Anxiety Disorders and Depression by Targeting Excessive Worry and Rumination in Adolescents and Young Adults: A Randomized Controlled Trial. Behaviour Research and Therapy, 90, 123-136. https://doi.org/10.1016/j.brat.2016.12.015

Trull, T. J., \& Durrett, C. A. (2005). Categorical and Dimensional Models of Personality Disorder. Annual Review of Clinical Psychology, 1, 355-380. https://doi.org/10.1146/annurev.clinpsy.1.102803.144009

Tully, P. J., Zajac, I. T., \& Venning, A. J. (2009). The Structure of Anxiety and Depression in a Normative Sample of Younger and Older Australian Adolescents. Journal of $A b$ normal Child Psychology, 37, 717-726. https://doi.org/10.1007/s10802-009-9306-4

van Heugten-van der Kloet, D., \& van Heugten, T. (2015). The Classification of Psychiatric Disorders According to DSM-5 Deserves an Internationally Standardized Psychological Test Battery on Symptom Level. Frontiers in Psychology, 6, 1108.

https://doi.org/10.3389/fpsyg.2015.01108

Wakefield, J. C., \& First, M. B. (2012). Validity of the Bereavement Exclusion to Major Depression: Does the Empirical Evidence Support the Proposal to Eliminate the Exclusion in DSM-5? World Psychiatry, 11, 3-10.

https://doi.org/10.1016/j.wpsyc.2012.01.002

Werner-Seidler, A., Perry, Y., Calear, A. L., Newby, J. M., \& Christensen, H. (2017). School-Based Depression and Anxiety Prevention Programs for Young People: A Systematic Review and Meta-Analysis. Clinical Psychology Review, 51, 30-47. https://doi.org/10.1016/j.cpr.2016.10.005

Widiger, T. A. (Ed.) (2012). The Oxford Handbook of Personality Disorders. Oxford: Oxford University Press. https://doi.org/10.1093/oxfordhb/9780199735013.001.0001

Young, J. E., Klosko, J. S., \& Weishaar, M. E. (2006). Schema Therapy: A Practitioner's Guide. New York: Guilford Press.

Zald, D. H., \& Lahey, B. B. (2017). Implications of the Hierarchical Structure of Psycho- 
pathology for Psychiatric Neuroimaging. Biological Psychiatry: Cognitive Neuroscience and Neuroimaging, 2, 310-317. https://doi.org/10.1016/j.bpsc.2017.02.003

Zimmerman, M. (2011). A Critique of the Proposed Prototype Rating System for Personality Disorders in DSM-5. Journal of Personality Disorders, 25, 206-221.

https://doi.org/10.1521/pedi.2011.25.2.206 